\title{
Study on the Applicability of Elastic Recovery (Resilience) Experiment for Asphalt-Rubber
}

\author{
Zechen Yao $(1),{ }^{1}$ Renfeng Yang, ${ }^{1}$ Jian Kang, ${ }^{2}$ and Zhigang Zhang ${ }^{3}$ \\ ${ }^{1}$ School of Construction Machinery, Chang'an University, Xi'an 710064, China \\ ${ }^{2}$ Hebei Transportation Investment Group Corporation, Zhangjiakou, Hebei 075000, China \\ ${ }^{3}$ Yanchong Temporary Preparatory Office of Hebei Province Expressway, Zhangjiakou, Hebei 075400, China
}

Correspondence should be addressed to Zechen Yao; 372896087@qq.com

Received 17 July 2021; Revised 22 September 2021; Accepted 22 December 2021; Published 4 January 2022

Academic Editor: Okan Sirin

Copyright ( $\odot 2022$ Zechen Yao et al. This is an open access article distributed under the Creative Commons Attribution License, which permits unrestricted use, distribution, and reproduction in any medium, provided the original work is properly cited.

In this paper, the applicability of the elastic recovery (resilience) experiment for asphalt-rubber (AR) binders has been quantitatively assessed. The mechanical model, based on the viscoelastic constitutive relation and particle inclusion theory, was developed. The interfacial detachment between crumb rubber (CR) particles and asphalt caused by stress concentration was analyzed with Weibull statistical equations. Based on the road roughness excitation, the vehicle-road coupling vibration model was established to analyze the impact of vehicle loading on road surface deformation. AR binders with different CR particle sizes were assessed using scanning electron microscope (SEM) imaging and prepared for testing the elastic recovery (resilience). The results showed that the greater internal stress caused by the longer stretch length of AR binders in the elastic recovery experiment was ten times higher than that obtained from the resilience experiment, leading to the interfacial detachment between asphalt and the CR particles. Hence, the elastic property of some of the CR particles with high modulus was not reflected, resulting in the test values being lower than actual values. With the reduction of CR particle size, the interfacial detachment was improved in the elastic recovery experiment due to intense material interchange and the enhancement of interfacial bond strength. The millimeterscale compression deformation of the AR binder in the resilience experiment was closer to the actual deformation of the road surface. The experimental time of resilience $(120 \mathrm{~min})$ has been reported less than that for elastic recovery $(200 \mathrm{~min}-230 \mathrm{~min})$. This study shows that the resilience experiment has a significant advantage in assessing the elastic property of the AR binder.

\section{Introduction}

The use of modifiers for improving the performance of asphalt pavements has always been the area of interest among researchers [1-3]. Asphalt-rubber (AR) is made by adding Crumb Rubber (CR) into the asphalt. AR can solve the environmental issues arising from the waste tires and improve the road performance of asphalt by using the effective properties of CR particles [4, 5]. Currently, researchers are focusing more on the modification mechanism and production formula of AR [4-9], and there is little research on the evaluation system of AR. Hence, the evaluation system has not been unified for AR around the world. However, the core evaluation indices mainly include needle (cone) penetration, elastic recovery (resilience), viscosity, and softening point [10].
Elastic recovery (resilience) is an important index to evaluate the elastic performance for AR binder, and there are some differences between these two evaluation mechanisms. The elastic recovery experiment is primarily used to determine the elastic recovery of the AR binder after a long stretch. In contrast, the resilience experiment is used to evaluate the springback recovery of the AR binder after compression. The elastic recovery at $25^{\circ} \mathrm{C}$ following SBS modified asphalt evaluation system is mainly used in AR local technical standards in China [11]. However, the United States (ASTM D6114-19 [12], D5329-15 [13]), South Africa, and Italy have selected resilience to evaluate the AR binder [14]. Exploring the applicability of the elastic recovery (resilience) experiment for AR binders is greatly significant in accurately evaluating the elastic property of $A R$ and popularizing its applications. 
There have been limited studies on elastic recovery (resilience) experiments. Dasek et al. [15] studied the elastic property of CR modified asphalt by two elastic recovery (resilience) experiments, and these test methods were considered to be valid. Yang et al. [10] suggested that the resilience experiment should be used to assess the elastic property of AR binders due to the presence of CR particles. The findings of Liu and $\mathrm{Li}$ [16] confirmed that resilience was more suitable for evaluating the elastic property of $A R$ binders, which could better characterize the elastic performance at a small scale. Hao et al. [11] put forward that the elastic recovery experiment reflected the stretch recovery ability for AR binders, whereas the resilience experiment reflected the compression recovery ability for AR binders, which was more effective in characterizing the elastic property of AR mixtures. Wang [14] demonstrated that the experimental results of resilience were not impacted by stress concentration around CR particles, which was more scientifically appropriate and reasonable. Although significant progress has been made in research on the elastic experiment of AR binders, there are still several limitations. Most of these studies have only been carried out using simple elastic recovery (resilience) experiments or qualitative analysis for AR binders. The research studies on the applicability of elastic recovery (resilience) experiments for AR binders from CR modification mechanism and theoretical analysis standpoints are sparse.

Combining the CR modification mechanism and detection principle of elastic recovery (resilience) experiment, a mechanical model based on the viscoelastic constitutive relation and particle inclusion theory of composite materials has been developed in this paper. The Weibull statistical equation was used to analyze the interfacial detachment of asphalt and CR particles in the two experiments. Combining SEM observations, the influence model of CR particle size for interfacial detachment was obtained. Based on the road roughness excitation, the applicability of these two evaluation indices was explored from the actual road deformation computed by vehicle-road coupling vibration equation using MATLAB. Elastic recovery (resilience) experiments on AR binders with different CR particle sizes were carried out to verify the correctness of the theoretical analysis. This paper provides a theoretical basis and justification for using resilience to evaluate the AR binders.

\section{Experiments}

2.1. Materials. The asphalt in this study was a pure asphalt binder with 70 penetration grade obtained from the LuZheng company in China. Ambient grinding CR of \#20, \#30, $\# 40$, \#60, and \#80 mesh produced by HuaYi company in China were used to prepare AR binders. The main technical parameters are given in Tables 1 and 2.

2.2. Preparation of AR Binders. The wet process was used to prepare the AR binders. The \#20, \#30, \#40, \#60, and \#80 mesh CR ( $20 \%$ by the weight of asphalt) was mixed with the base asphalt to prepare AR binders. The AR binders were
TABle 1: Main technical indexes of base asphalt.

\begin{tabular}{lcccc}
\hline Experiment item & Unit & $\begin{array}{c}\text { Quality } \\
\text { index }\end{array}$ & $\begin{array}{c}\text { Test } \\
\text { method }\end{array}$ & Results \\
\hline $25^{\circ} \mathrm{C}$ needle & $0.1 \mathrm{~mm}$ & $60 \sim 80$ & $\mathrm{~T} 0604$ & 69.2 \\
penetration & - & $-1.5 \sim+1.0$ & $\mathrm{~T} 0604$ & -1.22 \\
Penetration index & ${ }^{\circ} \mathrm{C}$ & $\geq 46$ & $\mathrm{~T} 0606$ & 47.24 \\
Softening point & $\mathrm{cm}$ & $\geq 100$ & $\mathrm{~T} 0605$ & $100+$ \\
$15^{\circ} \mathrm{C}$ force ductility & $\%$ & $\geq 99$ & $\mathrm{~T} 0607$ & 99.56 \\
Solubility & ${ }^{\circ} \mathrm{C}$ & $\geq 260$ & T0611 & 301 \\
Flash-point & $\mathrm{g} / \mathrm{cm}^{3}$ & - & - & 1.034 \\
$15^{\circ} \mathrm{C}$ density & & & & \\
\hline
\end{tabular}

obtained by adding CR to base asphalt, which was melted at $80-90^{\circ} \mathrm{C}$ previously. Manual stirring for 5 minutes was done to disperse $\mathrm{CR}$ in the base asphalt efficiently and then blended using a high-speed mixer (at about $1000 \mathrm{rpm}$ ) at $180^{\circ} \mathrm{C}\left( \pm 5^{\circ} \mathrm{C}\right)$ for 45 minutes, in accordance with ASTM D6114-19 [12].

2.3. Experimental Methods. To analyze the impact of finer $\mathrm{CR}$ particles on the interfacial detachment, the AR binders with \#40, \#60, and \#80 mesh CR were observed using FEI Quanta FEG 250 FESEM following GB/T 16594-08 [17]. The $\mathrm{AR}$ binders were tested for elastic recovery and resilience at $25^{\circ} \mathrm{C}$ using a bitumen ductility meter (SYD-4508G-1) and a digital penetration meter (SYD-2801L) conforming to NB/ SH/T 0737-14 [18] and ASTM D5329-15 [13], respectively.

\section{Mechanical Model in Elastic Recovery (Resilience) Experiment}

In this section, the mechanical model was developed to explore the applicability of the elastic recovery (resilience) experiment for AR binder. Figure 1 shows the schematic illustrations of the detection mechanism for the elastic recovery (resilience) experiment. The yellow particles in the diagrams show CR particles. The elastic recovery experiment is mainly used to evaluate the elastic recovery of the AR binder after a longer stretch deformation $(10 \mathrm{~cm})$, whereas the resilience experiment is employed for evaluating the springback recovery of the AR binder after compression deformation (about $1 \mathrm{~cm}$ ).

AR binder is a solid-liquid two-phase material, in which the base asphalt is a kind of typical viscoelastic body. However, due to the potential of CR particles in absorbing the light component of asphalt in the reaction process, it is no longer a pure elastomer. To simplify the analysis, CR is regarded as a viscoelastic body whose modulus is higher than that of base asphalt. Since the experimental process of elastic recovery is carried out at constant speed [18], the strain inside the specimen is considered to increase linearly. Using the Kelvin model to analyze the loading process, the elastic modulus and the damping of CR particles and base asphalt are represented as $L_{1}, \eta_{1}, L_{0}, \eta_{0}$, respectively, as shown in Figure 2(a). The stress-strain relationship is, $\sigma=L \mathcal{E}+\eta \dot{\mathcal{\varepsilon}}$, as shown in Figure 2(b).

According to Eshebly's inclusion theory [19] and MoriTanaka's homogenization theory $[20,21]$, 
TABLE 2: Main technical indexes of CR.

\begin{tabular}{lccccc}
\hline Density $\left(\mathrm{g} / \mathrm{cm}^{3}\right)$ & Water $(\%)$ & Ash $(\%)$ & Rubber content $(\%)$ & Fiber content $(\%)$ & Burning residual $(\%)$ \\
\hline 1.12 & 0.6 & 4.5 & 51 & 0.5 & 37.5 \\
\hline
\end{tabular}

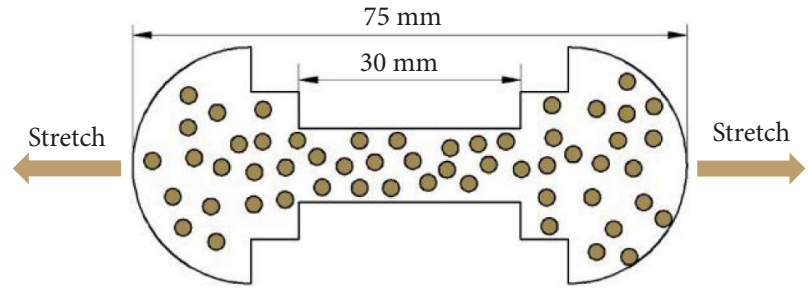

(a)

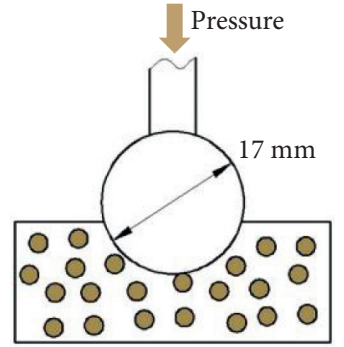

(b)

FIGURE 1: Schematic diagrams of detection mechanism for elastic recovery (resilience) experiment. (a) Elastic recovery experiment; (b) resilience experiment.

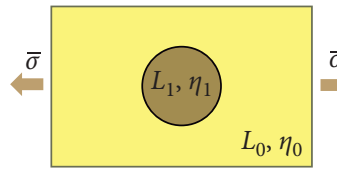

(a)

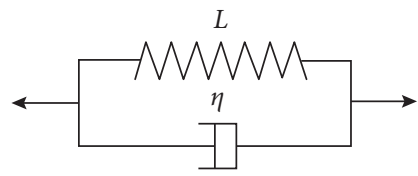

(b)

FIGURE 2: Loading process analysis.

$$
\begin{aligned}
\bar{\sigma}^{(1)}= & \bar{\sigma}+\widehat{\sigma}+\sigma^{p t}=L_{1}\left(\varepsilon_{0}+\widehat{\varepsilon}+\varepsilon^{p t}\right) \\
& +A_{1}=L_{0}\left(\varepsilon_{0}+\widehat{\varepsilon}+\varepsilon^{p t}-\varepsilon^{*}\right)+A_{1} \\
\bar{\sigma}^{(0)}= & \bar{\sigma}+\widehat{\sigma} \\
\mathcal{E}^{p t}= & S \varepsilon^{*} \\
\bar{\sigma}= & c_{1} \bar{\sigma}^{(1)}+c_{0} \bar{\sigma}^{(0)}
\end{aligned}
$$

where $\bar{\sigma}^{(1)}$ is the stress of CR particles; $\bar{\sigma}^{(0)}$ is the stress of base asphalt; $\bar{\sigma}$ is the external stress; $\varepsilon_{0}$ is the external strain; $\widehat{\sigma}$ is the difference between $\bar{\sigma}^{(0)}$ and $\bar{\sigma} ; \widehat{\varepsilon}$ is the difference between the strain of base asphalt and $\varepsilon_{0} ; \sigma^{p t}$ is the difference between $\bar{\sigma}^{(0)}$ and $\bar{\sigma}^{(1)} ; \varepsilon^{p t}$ is the difference between the strain of base asphalt and the strain of CR particles; $\varepsilon^{*}$ is Eigenstrain; $c_{1}$ and $c_{0}$ are the volume content of CR particles and base asphalt, respectively; $S$ is Eshelby tensor related to the property of matrix material and particle shape; and $A_{i}$ represents a constant.

According to equation (1) through equation (4),

$$
\widehat{\mathcal{\varepsilon}}=-c_{1}(S-I) \varepsilon^{*}+A_{2} .
$$

According to (1) and (5),

$$
\begin{aligned}
\mathcal{E}^{*}= & -\left\{\left(L_{1}-L_{0}\right]\left[S+(I-S) c_{1}+A_{3}\right]+L_{0}\right\}^{-1} \\
& \left(\left(L_{1}-L_{0}\right) \varepsilon_{0}+A_{4}\right) .
\end{aligned}
$$

According to (6),

$$
\bar{\sigma}^{(1)}=L_{0}\left((I+G) \varepsilon_{0}+\frac{G A_{4}}{\Delta L}\right)+A_{1}
$$

where $G=c_{0}\left\{\left(L_{1}-L_{0}\right]\left[S+(I-S) c_{1}+A_{3}\right]+L_{0}{ }^{-1}\left(L_{1}-L_{0}\right)\right.$ $(I-S)$ and

$$
\Delta L=L_{1}-L_{0}
$$

The aforementioned analysis is aimed at specimen deformation in multiple directions in space. As the experimental progress of elastic recovery (resilience) is unidirectional tension, the parameters in a single direction are only considered to simplify the analysis further. Let $\varepsilon_{0}=\Delta x / x_{0}$, where $\Delta x$ is the stretch length and $x_{0}$ is the original length of the specimen. Then, (7) can be converted into

$$
\bar{\sigma}^{(1)}=L_{0}\left((I+G) \frac{\Delta x}{x_{0}}+\frac{G A_{4}}{\Delta L}\right)+A_{1} .
$$

When $\Delta L$ is constant, it can be seen that stress in particles increases linearly with the stretch length $\Delta x$. Meanwhile, this equation can also be used to analyze the compression progression of the resilience experiment. As the deformation of elongation and compression is about $10 \mathrm{~cm}$ and $1 \mathrm{~cm}$, respectively, according to (9), the stress in $\mathrm{CR}$ particles in the elastic recovery experiment is about ten times that of the resilience experiment. Therefore, compared with the resilience experiment, more severe stress concentration may occur in the elastic recovery experiment, which may cause interfacial detachment of the CR particles and 
base asphalt. The Weibull statistical model can be used to describe the accumulation probability of interface detachment [21]:

$$
P\left(\bar{\sigma}^{(1)}\right)=1-e^{\left[-\left(\bar{\sigma}^{(1)} / S_{0}\right)^{m}\right]},
$$

where $\bar{\sigma}^{(1)}$ is CR particle stress and $S_{0}$ and $m$ are scale and shape parameters, respectively. As it is tough to determine the accurate values of $S_{0}$ and $m$, Figure 3 shows the detachment probability curve with common values [21] calculated by MATLAB. It is observed that when the difference of particle stress is ten times, it is easy to appear detachment ultimately (the probability reaches 1 ) between CR particles and base asphalt in elastic recovery experiments, whereas rarely detachment occurs in resilience experiments.

Figure 4 intuitively illustrates the detachment process of CR particles and base asphalt in the elastic recovery experiment. As shown in Figure 4(a), the CR particles and base asphalt bear stress simultaneously at the beginning of the stretch, and no detachment occurs in the specimen. As shown in Figure 4(b), due to the difference in elasticity modulus, adhesive failure occurs with the increase of stretch length, and the corresponding stress transferred by CR particles is reduced. It is also evident from Figure 4(c) that when the specimens show complete detachment, CR particles have already lost the capacity of transfer stress in the experiment, which was replaced by adjacent base asphalt. In other words, the high elasticity of some of the CR particles cannot be detected due to detachment, resulting in the values of experimental results being lower than the actual values. Hence, the elastic recovery experiment may not accurately determine the elastic property of AR binders compared with the resilience experiment.

Figures 5(a) and 5(b) show the schematic diagrams of AR specimens with different CR particle sizes (same content). It can be clearly seen that the contact area between CR particles and asphalt increases with the reduction of CR particle size. On one hand, the increase in contact area intensifies the reaction between the $\mathrm{CR}$ particles and asphalt, thereby improving the material interface and reducing the difference of elastic modulus between asphalt and CR, which reduces stress concentration. In addition, the increase of contact area improves the bonding area between CR particles and asphalt, meaning that the interfacial bond strength is improved. Therefore, with the reduction of CR particle size, the interfacial detachment between CR particles and asphalt is improved in the elastic recovery experiment.

\section{Experimental Results}

4.1. Observations of $A R$ Binders. Figure 6 shows the AR binders with different $C R$ particle sizes. Noticeable $C R$ particles can be observed in AR binders with \#20 and \#30 $\mathrm{CR}$. Tiny CR particles distributed within the AR binders with \#40, \#60 CR can also be observed. However, CR particles cannot be observed in AR binders with \#80 CR macroscopically. The SEM images of AR binders with \#40, \#60, and \#80 CR are shown in Figure 7. The gray particles shown in the images are the CR particles. Figure 7(a) shows that the
AR binder with \#40 CR has many noticeable gray particles indicating distinct solid-liquid two-phase features. With the reduction of $\mathrm{CR}$ particle size, this solid-liquid two-phase feature gradually weakens. In Figure $7(\mathrm{c})$, the two-phase continuous blending structure system constituted by asphalt and $\mathrm{CR}$ is formed due to severe reactions, indicating the intense material interchange occurred, and CR particles are no longer independent in base asphalt, which is consistent with the previously published findings in the literature [22]. Therefore, the interfacial detachment between CR particles and asphalt can be improved by reducing CR particle size. This corroborates the theoretical analysis in Section 3.

\subsection{Experimental Results for Elastic Recovery (Resilience).} Figures 8 and 9 show the AR binders with \#20-80 CR in the experimental process for elastic recovery (resilience) at

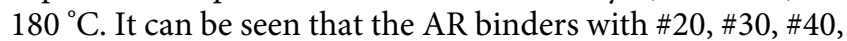
and \#60 CR have obvious holes (silver holes shown in white circle) in the stretching process of elastic recovery experiments, whereas only some cracks occur in the AR binders with \#80 CR. As shown in Figure 9, there are no apparent holes and cracks in AR binders in resilience experiments. It can be seen intuitively that the detachment phenomenon in elastic recovery experiments is much severe than that in resilience experiments. It shows that under the condition of longer stretch length in elastic recovery experiment, AR binders with coarser $\mathrm{CR}$ are more likely to exhibit stress concentration, leading to the interfacial detachment of CR particles and asphalt easily, with the subsequent appearance of the holes. There are no apparent holes, and cracks appeared in AR binders in resilience experiments. The experimental results are consistent with the theoretical analysis in Section 3. It is worth mentioning that only holes and cracks on the surface of the specimen can be observed, and it is reasonable to speculate that many invisible cracks and holes are generated inside specimens in elastic recovery experiments.

To intuitively analyze the experimental progress of elastic recovery (resilience) for AR binders, the schematic diagrams of AR binders before and after stretching (compressing) are shown in Figure 10. Figure 10(a) shows that the CR particles are uniformly distributed in asphalt before stretching, and the interface is well bonded. With the stretching of the AR binder, the stress concentration occurs in the specimen due to the difference in elasticity modulus. When internal stress is higher than the interfacial bond strength between asphalt and CR particles, the interfacial detachment starts, and cracks and holes appear in the specimens. When the holes are generated in the AR binders, the CR particles (red particles in Figure 10(b)) located within the hole region can no longer transfer stress. The bearing capacity is eventually lost. Hence, the nearby asphalt bears the stretching deformation and subsequent elastic recovery, as shown in Figure 10(b). This indicates that the elastic property of some CR particles with high modulus cannot be tested in the experiments (red particles in Figure 10(b)), leading to the test values being lower than actual values. In other words, this experimental method cannot accurately 


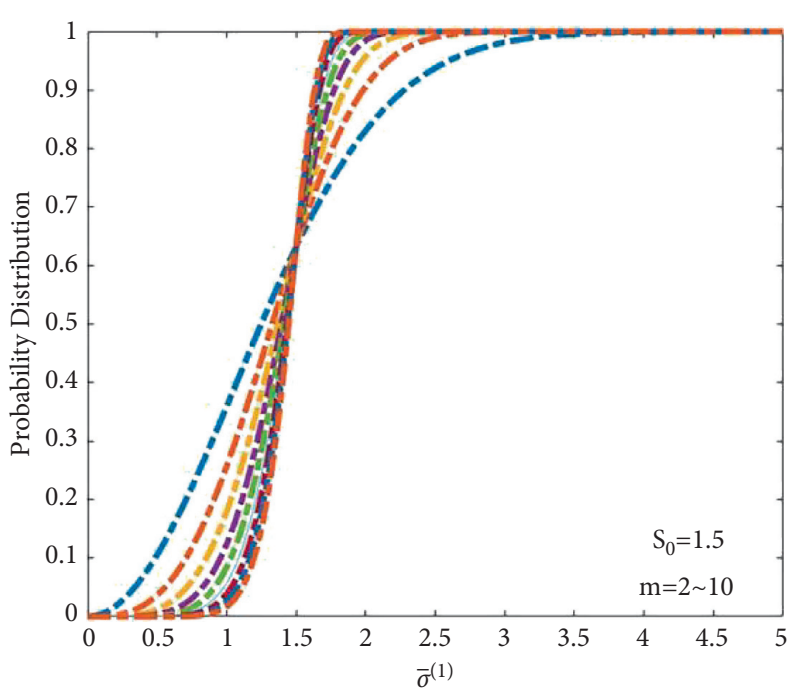

(a)

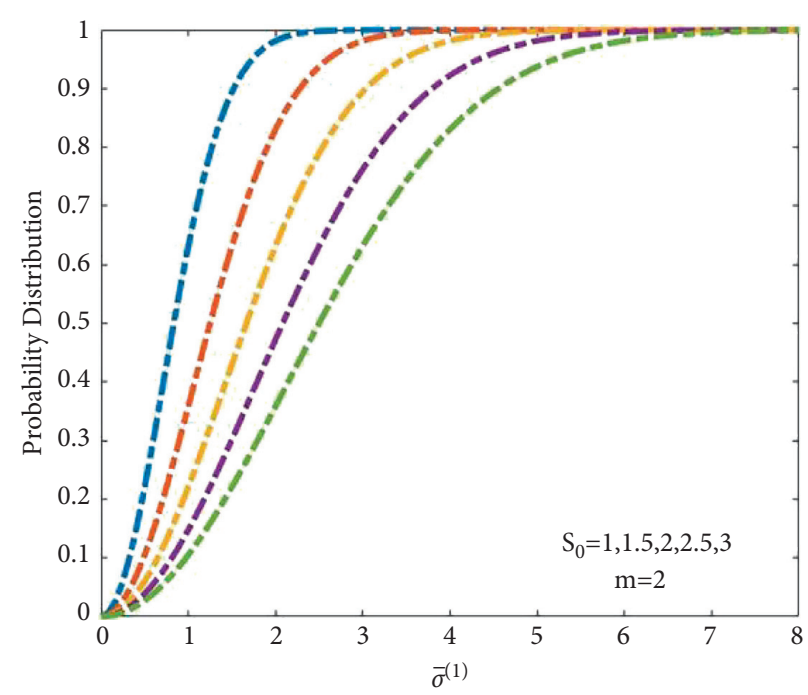

(b)

FIgURE 3: Prediction of detachment possibility with common values.

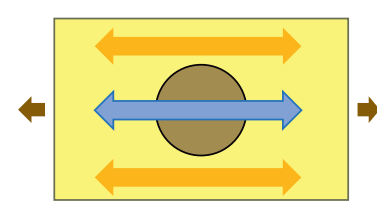

(a)

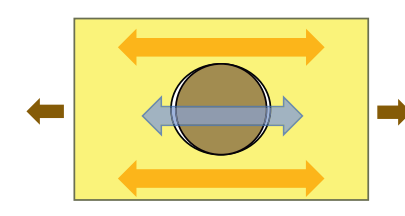

(b)

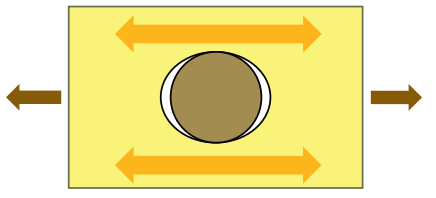

(c)

FIGURE 4: Detachment process of CR particles and base asphalt in elastic recovery experiment. (a) No detachment, (b) partial detachment, and (c) completely detachment.

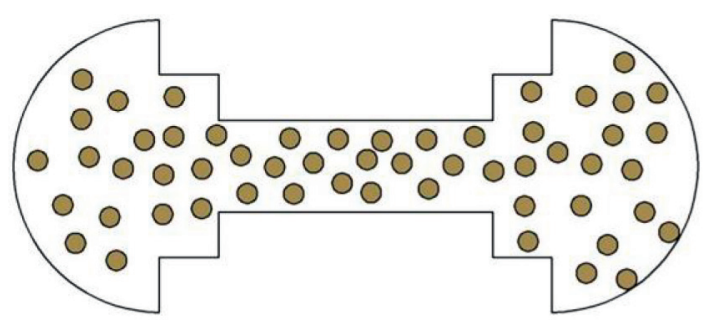

(a)

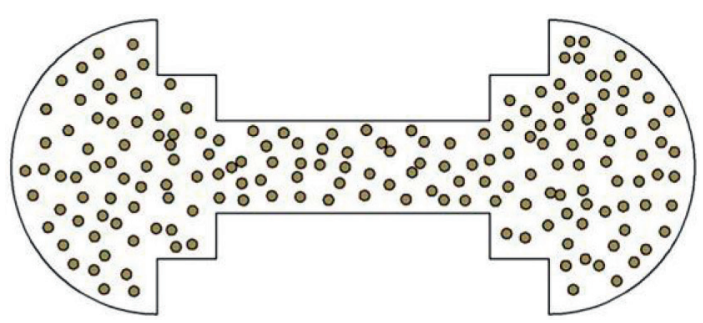

(b)

FIgure 5: AR specimens with different CR particle sizes. (a) AR specimen with coarse CR particles and (b) AR specimen with fine CR particles.

reflect the elastic properties of both CR and asphalt. The compressive deformation is small in the resilience experiment, so it is challenging to ascertain interfacial detachment caused by stress concentration in AR binders, and the elastic property of both asphalt and CR can be reflected. Hence, the resilience experiment may be more suitable for evaluating AR binders, particularly for AR binders with coarser CR particles. Due to the difference between these two detection mechanisms, it is of little significance to compare the results of elastic recovery experiments and resilience experiments [23]. Therefore, it is not analyzed in this paper.

It is worth noting that the experimental time of resilience $(120 \mathrm{~min})$ is significantly less than that of elastic recovery
(200 min-230 min) according to the stipulations in ASTM D5329-15 [13] and NB/SH/T 0737-14 [18], which shows the usefulness of the resilience experiment in terms of saving experimental time.

\section{Impact of Vehicle Loading on Road Surface Deformation}

The purpose of the elastic recovery (resilience) experiment is to evaluate the elastic property of the AR binder. Good elastic property can effectively reduce the residual deformation of road materials and improve the cracking resistance $[14,24]$. However, in the actual service process of asphalt pavement, it 


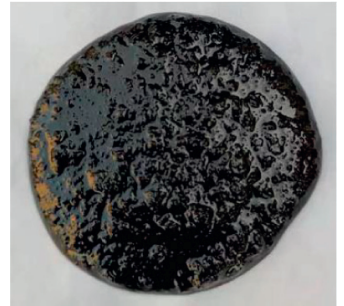

(a)

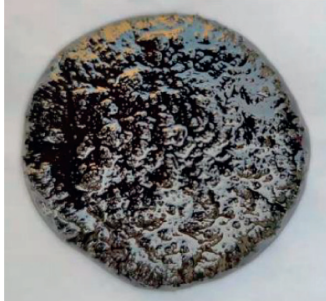

(b)

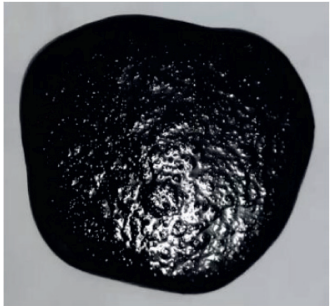

(c)

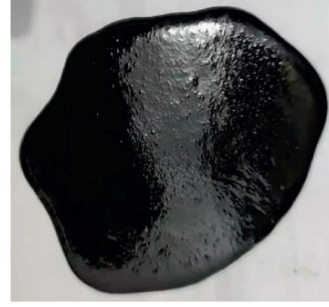

(d)

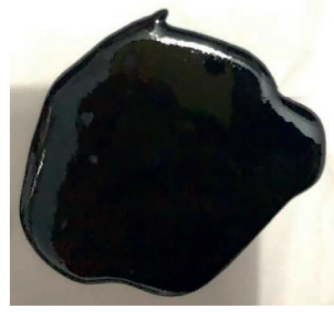

(e)

FIGURE 6: AR binders with different CR particle sizes. (a) AR with \#20 CR, (b) AR with \#30 CR, (c) AR with \#40 CR, (d) AR with \#60 CR, and (e) AR with \#80 CR.

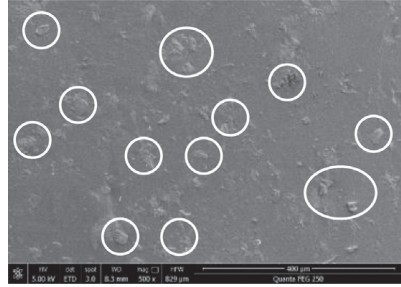

(a)

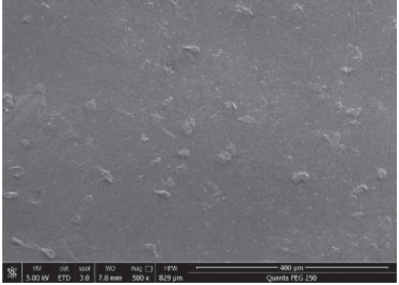

(b)

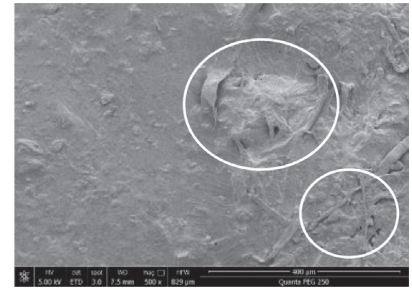

(c)

FIgURE 7: SEM images of AR binders with different CR particle sizes. (a) AR with \#40 CR, (b) AR with \#60 CR, and (c) AR with \#80 CR.

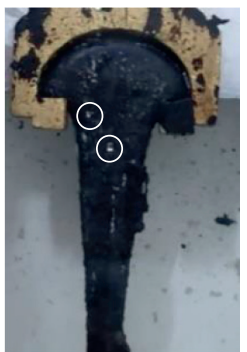

(a)

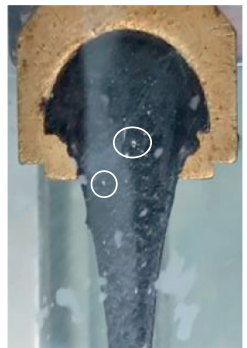

(b)

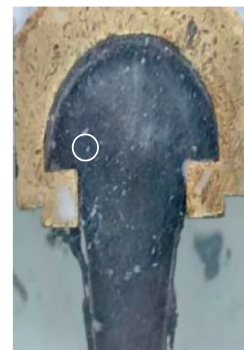

(c)

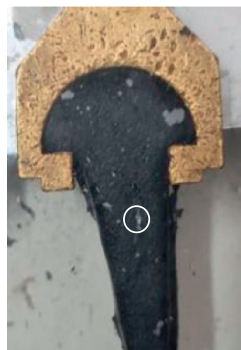

(d)

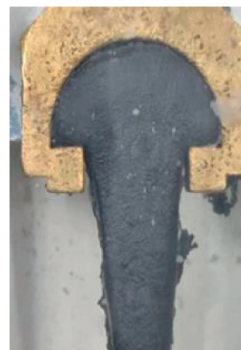

(e)

FIGURE 8: AR binders with \#20-80 CR in the experimental procedure for elastic recovery at $180^{\circ} \mathrm{C}$. (a) AR with \#20 CR, (b) AR with \#30 CR, (c) AR with \#40 CR, (d) AR with \#60 CR, and (e) AR with \#80 CR.

is worth determining whether it is necessary to use such a long stretch length $(10 \mathrm{~cm})$ in an elastic recovery experiment to evaluate the elastic property of the AR binder. In this section, based on the road roughness excitation, the road surface deformation caused by vehicles with different overload conditions under various pavement grades was computed by the vehicle-road coupling vibration model and finite element model to evaluate the applicability of elastic recovery (resilience) experiment for AR binders.

5.1. Vehicle-Road Coupling Vibration Model. Extensive experiments and analysis by the automobile industry show that the quarter vehicle model is quite successful in predicting the 


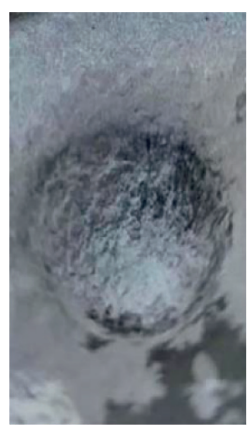

(a)

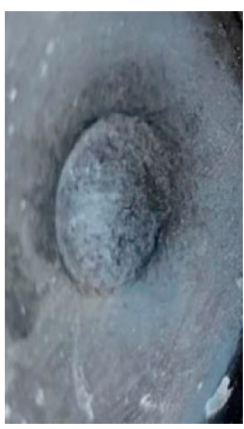

(b)

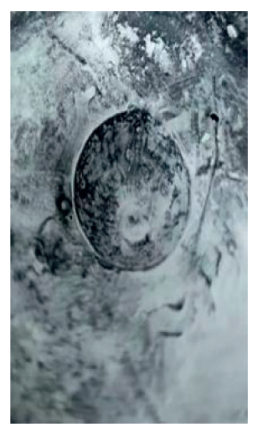

(c)

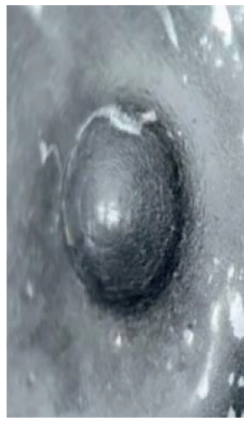

(d)

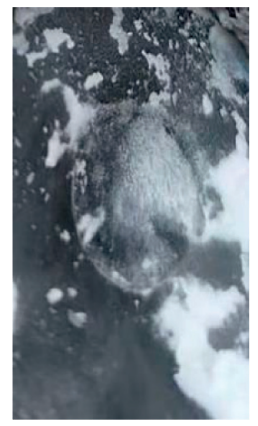

(e)

FIgURE 9: AR binders with \#20-80 CR in the experimental procedure for resilience at $180^{\circ} \mathrm{C}$. (a) AR with \#20 CR, (b) AR with \#30 CR, (c) AR with \#40 CR, (d) AR with \#60 CR, and (e) AR with \#80 CR.

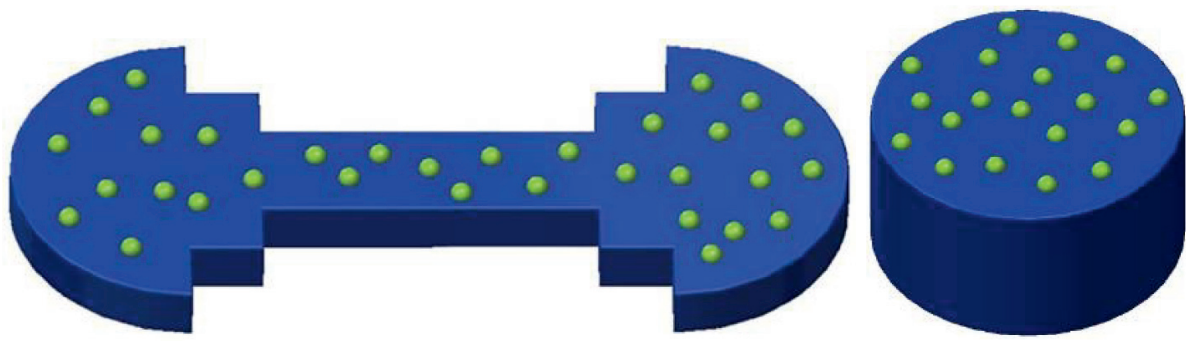

(a)

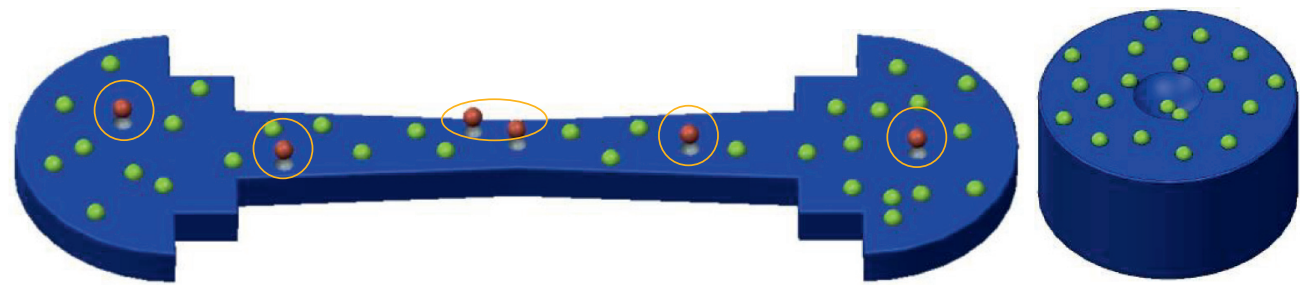

(b)

FIGURE 10: Schematic diagrams of AR specimens (a) before stretching (compressing) and (b) after stretching (compressing).

vertical vibration acceleration of vehicles, and there is no need to build a multidegree of freedom model [25]. The model is shown in Figures 11 and 12.

The dynamic equation of the vibration system is as follows:

$$
\begin{gathered}
m_{s} \ddot{y}_{s}+c_{s}\left(\dot{y}_{s}-\dot{y}_{t}\right)+k_{s}\left(y_{s}-y_{t}\right)=0, \\
m_{t} \ddot{y}_{t}+c_{t}\left(\dot{y}_{t}-\dot{y}_{r}\right)+k_{t}\left(y_{t}-y_{r}\right) \\
-c_{s}\left(\dot{y}_{s}-\dot{y}_{t}\right)-k_{s}\left(y_{s}-y_{t}\right)=0
\end{gathered}
$$

where $m_{s}$ is suspension system mass; $m_{t}$ is nonsuspension system mass; $k_{s}$ is suspension system stiffness; $k_{t}$ is nonsuspension system stiffness; $y_{s}$ and $y_{t}$ are the vertical displacements of the suspension system and nonsuspension system, respectively; and $y_{r}$ is vertical displacement excitation of road surface roughness. The additional random dynamic load of vehicle on the road surface is as follows:

$$
F(t)=c_{t}\left(\dot{y}_{t}-\dot{y}_{r}\right)+k_{t}\left(y_{t}-y_{r}\right) \text {. }
$$

The dynamic load factor is as follows:

$$
D=\frac{P_{0}+F(t)_{\max }}{P_{0}}=\frac{F(t)_{\max }}{P_{0}}+1,
$$

where $P_{0}=\left(m_{s}+m_{t}\right) g$ and $F(t)_{\max }$ is maximum additional dynamic load.

5.2. Simulation Model. Currently, the researchers usually use Power Spectral Density (PSD) to represent the road surface roughness [25]. ISO/TC 108/SCN67 (Draft method for representation of road surface roughness) [26] and GB 7031 (vehicle vibration-describing method for road surface irregularity) [27] propose the classifications of road surface roughness according to PSD. Table 3 shows the geometric average of roughness coefficient $G_{0}$ with different road surface grades [28].

Due to the uncertainty in road surface roughness, it is difficult to use an analytical formula to calculate the road loading. Hence, it is an excellent method to use a software to generate the excitation functions according to different grades of the road surface. The simulation of white noise 


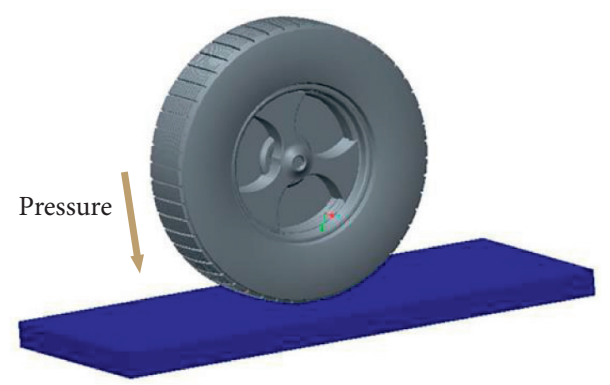

FIgURE 11: Vehicle-road contacting diagram.

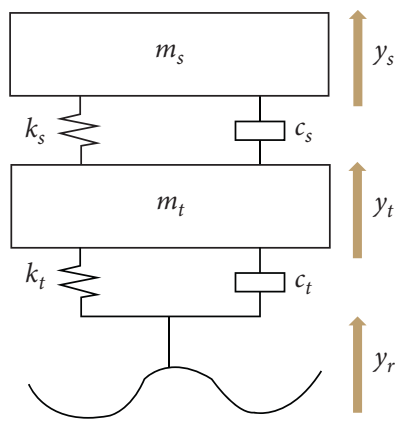

FIGURE 12: Vehicle-road coupling vibration model.

TABLE 3: Classification standard of road surface roughness in ISO/TC 108/SCN67.

\begin{tabular}{lccc}
\hline Road surface grades & & $G_{0} \times 10^{-6}\left(\mathrm{~m}^{2} \cdot \mathrm{c} . \mathrm{m}^{-1}\right)$ & \\
Upper limit & Geometric average \\
\hline$A$ & Lower limit & 32 & 16 \\
$B$ & 8 & 128 & 64 \\
$C$ & 32 & 512 & 256 \\
$D$ & 128 & 2048 & 1024 \\
$E$ & 512 & 8192 & 4096 \\
$G$ & 2048 & 32768 & 16384 \\
$H$ & 8192 & 65536 & 131072 \\
\hline
\end{tabular}

excitation based on linear filtering is currently one of the most widely used methods. The mathematical model in the time domain is as follows:

$$
\dot{y}_{r}(t)=-2 \pi f_{0} y_{r}(t)+2 \pi n_{0} \sqrt{G_{0} u} w(t),
$$

where $f_{0}=0.0628 \mathrm{~Hz}$ is lower cut-off frequency [29]; $n_{0}=0.1 \mathrm{~m}^{-1}$ is reference space frequency; $G_{0}$ is roughness coefficient; $u$ is driving speed; and $w(t)$ is random white noise.

According to equations (10) through (14), the system was simulated by Simulink in MATLAB, and the model is shown in Figure 13. According to the model, the road surface loading caused by vehicles with different overload conditions under different road surface grades can be computed. The medium-sized vehicle is taken as the analysis object, and the structural parameters are shown in Table 4 [30].

5.3. Simulation Results. Figure 14 shows the simulation results of road surface loading $\left(F(t)_{\max }+P_{0}\right)$ caused by the medium-sized vehicle, with different overload conditions
$(0-80 \%)$, at the speed of $30 \mathrm{~m} / \mathrm{s}$ under different road surface grades $(A-H)$. It can be observed that road surface loading gradually increases with the decrease of road grade and the aggravation of overload conditions.

According to the simulation results of road surface loading, the road surface deformation caused by vehicles is analyzed using Abaqus software. The contact area between the tires and the road surface is $0.0672 \mathrm{~m}^{2}$ [31], with the total number of tires being four. The results of road surface loading are imported into Abaqus software to compute the road surface deformation. To simplify the model, the road surface is set as elastomer with elastic modulus $E=1400 \mathrm{Mpa}$ and density $\rho=2400 \mathrm{~kg} \mathrm{~m}^{-3}$ [32]. The pressure is set on the contacting surface between the tires and the road surface, while the bottom of the road surface is considered fully constrained. The model is verified by grid independence. The computed results are shown in Figures 15 and 16.

As shown in Figures 15 and 16, the road surface stress and road deformation increases significantly with the 


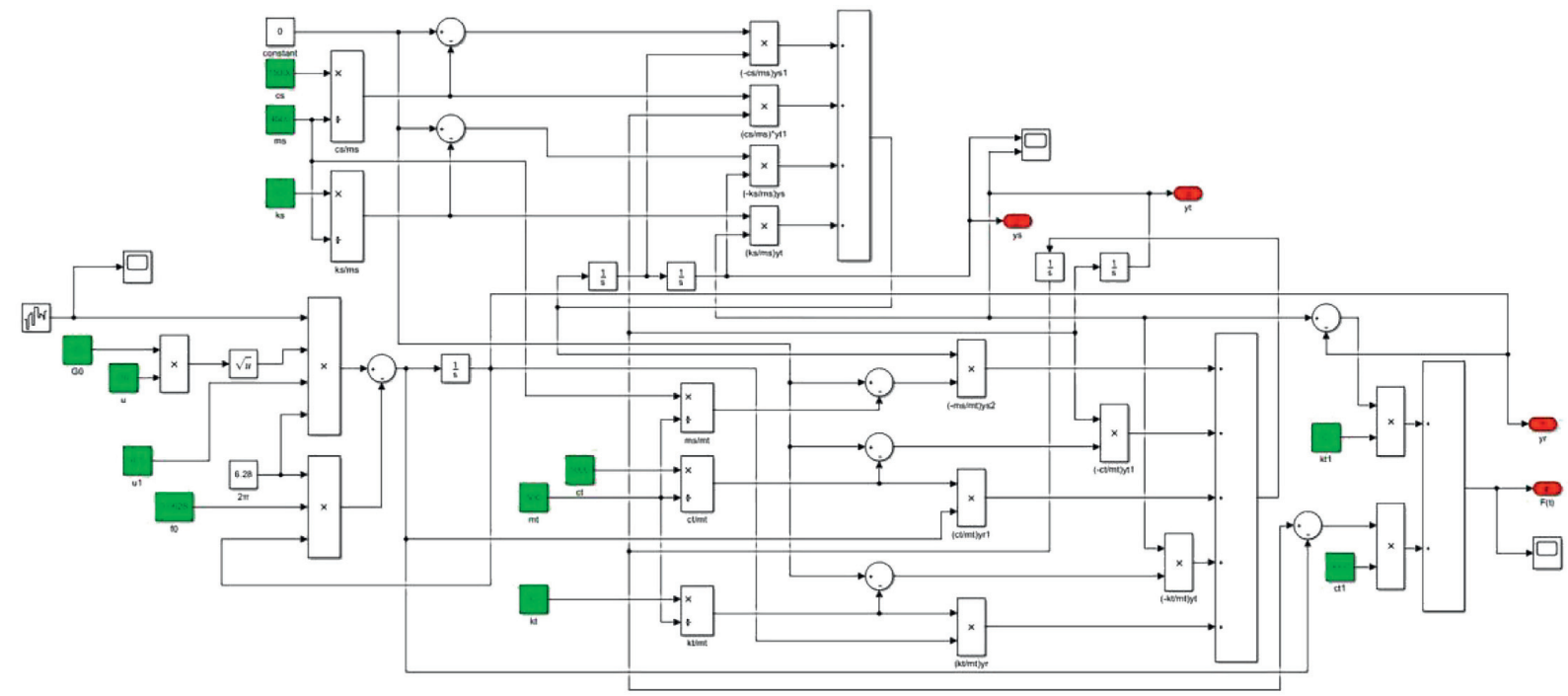

Figure 13: Vehicle-road coupling vibration simulation model based on the random excitation of road surface roughness.

TABLE 4: Medium-sized vehicle parameters.

\begin{tabular}{lccc}
\hline Parameter & Mass $(\mathrm{kg})$ & ${\text { Stiffness }\left(\mathrm{Kn} . \mathrm{m}^{-1}\right)}$ & ${\text { Damping }\left(\mathrm{Kn} . \mathrm{s} . \mathrm{m}^{-1}\right)}$ \\
\hline Suspension system & 4500 & 500 & 15 \\
Nonsuspension system & 500 & 1500 & 5 \\
\hline
\end{tabular}

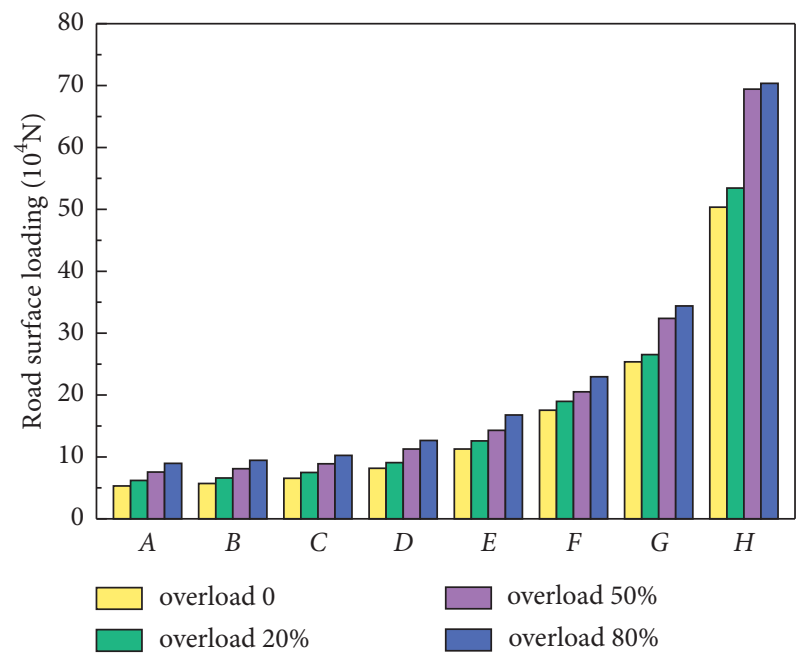

FIGURE 14: Impact of vehicle overload condition on road surface loading $(\mathrm{A} \sim \mathrm{H})$. 


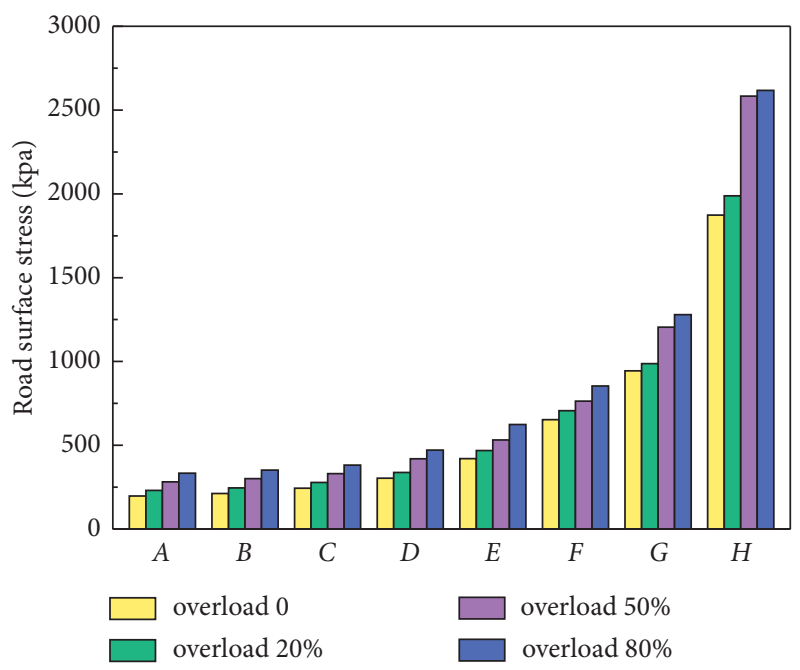

FIGURE 15: Impact of vehicle overload condition on road surface stress $(\mathrm{A} \sim \mathrm{H})$.

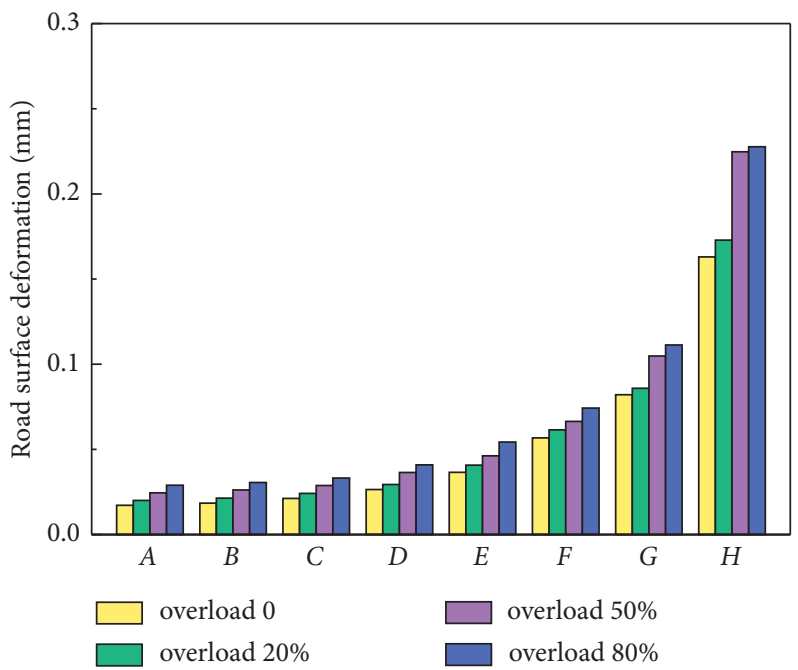

FIgURE 16: Impact of vehicle overload condition on road surface deformation $(A \sim H)$.

decrease of road grade and the aggravation of vehicle overload. However, even in the worst-case scenario $(80 \%$ overloading and $H$ grade road surface), the road surface deformation is about $0.3 \mathrm{~mm}$. This is consistent with the results in reference $[31,33,34]$. Hence, compared with a longer stretch length $(10 \mathrm{~cm})$ in the elastic recovery experiment, the detection mechanism of millimeter-scale compression springback recovery of resilience experiment is closer to the actual loading condition of the road surface.

\section{Summary and Conclusion}

In this paper, the particle inclusion theory and Kelvin model were used to analyze the detachment process of AR binder in elastic recovery (resilience) experiment, and the vehicle-road coupling vibration model and FEM were used to obtain the road surface deformation. Relevant experiments were carried out to verify the theoretical analysis. It is concluded that resilience has a significant advantage in evaluating the elastic property of AR binders. The key findings are summarized, and the conclusions drawn are given as follows:

(1) The longer stretch length of AR binders in the elastic recovery experiment easily generates greater internal stress in specimens, which is ten times higher than that obtained in the resilience experiment, resulting in severe stress concentration. The interfacial detachment between CR particles and asphalt occurs and generates holes in the specimens, destroying the continuity of the AR binder. Hence, some CR particles with high modulus cannot be tested during the elastic recovery experiment, resulting in lower experimental results than the actual values. The millimeter-scale compression deformation of AR binders in the resilience experiment is hardly influenced by the CR particles, indicating the real elastic property of AR binder containing asphalt and CR accurately. 
(2) With the increase of CR mesh number, the difference of elastic modulus between asphalt and CR is reduced, which is caused by the enhancement of material interface, and the contacting area between asphalt and CR is improved. This results in the reduction of stress concentration and the enhancement of interfacial bond strength, respectively, and as such, the interfacial detachment is improved in the elastic recovery experiment. Hence, it is only applicable to the evaluation of materials that are approximated to a single-phase body.

(3) Even in the worst-case scenario (80\% overloading and $H$ grade road surface), the actual compressive deformation of the road surface is below $1 \mathrm{~mm}$, which is closer to the force state of AR binders tested by the resilience experiment.

(4) The experimental time of resilience $(120 \mathrm{~min})$ is far less than that of elastic recovery (200 $\mathrm{min}-230 \mathrm{~min})$, which helps save time and reduce complexity.

\section{Data Availability}

The experimental data used in supporting these investigations are included within the research study.

\section{Conflicts of Interest}

The authors declare that they have no conflicts of interest regarding the publication of this study.

\section{Acknowledgments}

This work was supported by the Fundamental Research Funds for the Central Universities, CHD (grant no. 300102251711), and China Scholarship Council (grant no. 202006560027).

\section{References}

[1] A. Goli, H. Ziari, and A. Amini, "Influence of carbon nanotubes on performance properties and storage stability of SBS modified asphalt binders," Journal of Materials in Civil Engineering, vol. 29, no. 8, 2017.

[2] K. Z. Yan, Z. Hong, L. Y. You, J. Ou, and M. Miljković, "Influence of ethylene-vinyl acetate on the performance improvements of low-density polyethylene-modified bitumen," Journal of Cleaner Production, vol. 278, 2021.

[3] V. S. Punith, S. N. Suresha, S. Raju, S. Bose, and A. Veeraragavan, "Laboratory investigation of open-graded friction-course mixtures containing polymers and cellulose fibers," Journal of Transportation Engineering, vol. 138, no. 1, pp. 67-74, 2012.

[4] H. Wang, X. Liu, H. Zhang, P. Apostolidis, T. Scarpas, and S. Erkens, "Asphalt-rubber interaction and performance evaluation of rubberised asphalt binders containing nonfoaming warm-mix additives," Road Materials and Pavement Design, vol. 21, no. 6, pp. 1612-1633, 2020.

[5] R. Cao, Z. Leng, H. Yu, and S. C. Hsu, "Comparative life cycle assessment of warm mix technologies in asphalt rubber pavements with uncertainty analysis," Resources, Conservation and Recycling, vol. 147, pp. 137-144, 2019.
[6] H. B. Liu, M. S. Zhang, Y. B. Jiao, and L. Fu, "Preparation parameter analysis and optimization of sustainable asphalt binder modified by waste rubber and diatomite," Advances in Materials Science and Engineering, vol. 2018, Article ID 3063620, 14 pages, 2018.

[7] N. Lushinga, L. P. Cao, and Z. J. Dong, "Effect of silicone oil on dispersion and low-temperature fracture performance of crumb rubber asphalt," Advances in Materials Science and Engineering, vol. 2019, Article ID 8602562, 12 pages, 2019.

[8] H. Y. Yu, G. S. Deng, D. Y. Wang, and Z. Y. Zhang, "Warm Asphalt Rubber: A Sustainable Way for Waste Tire Rubber Recycling," Journal of Central South University, vol. 27, pp. 1-22, 2020.

[9] A. Hemida and M. Abdelrahman, "Influence of guayule resin as a bio-based additive on asphalt-rubber binder at elevated temperatures," Recycling, vol. 4, no. 3, 2019.

[10] R. F. Yang, Y. B. Dang, and A. G. Li, "Study on quality evaluation index of rubber asphalt," Highways, vol. 6, pp. 174-178, 2009.

[11] P. W. Hao, Z. H. Li, and J. Z. Xu, "Current standards for performance evaluation of rubberized asphalt," Road Machinery \& Construction Mechanization, vol. 32, no. 6, pp. 47-52, 2015.

[12] American Society for Testing Materials, Astm D6114-19, Standard specification for asphalt-rubber binder, American Society for Testing Materials, West Conshohocken, PA, USA, 2019.

[13] American Society for Testing Materials, Astm D5329-15, Standard test methods for sealants and fillers, hot-applied, for Joints and Cracks in Asphaltic and Portland Cement Concrete Pavements, American Society for Testing Materials, West Conshohocken, PA, USA, 2015.

[14] T. Q. Wang, Study on Evaluation Indexes of Rubber Asphalt and Technology of Warm Mix Rubber Asphalt SMA Mixture, pp. 32-44, Chang'an University, Xi'an, China, 2017.

[15] O. Dasek, P. Hyzl, and P. Coufalik, "Properties and ageing of crumb rubber modified bitumens," Key Engineering Materials, vol. 737, pp. 535-540, 2017.

[16] S. W. Liu and Z. H. Li, "Applying resilience to evaluate elasticity resuming performance of rubber asphalt," Journal of Highway and Transportation Research and Development, vol. 26, no. 7, pp. 22-26, 2009.

[17] Gb/T 16594, General Rules for Measurement of Length in Micron Scale by SEM, China National Standards, Beijing, China, 2008.

[18] Nb/Sh/T 0737-14, Standard test method for elastic recovery of asphalt materials by ductilometer, China National Energy Administration, Beijing, China, 2014.

[19] J. Eshelby, "The determination of the elastic field of an ellipsoidal inclusionand related problems," Proc. Roy. Soc, vol. 241, pp. 376-396, 1957.

[20] T. Mori and K. Tanaka, "Average stress in matrix and average elastic energy of materials with misfitting inclusions," Acta Metallurgica, vol. 21, no. 5, pp. 571-574, 1973.

[21] Y. H. Zhao, Micromechanics of Class of Damaged Composites, Tsinghua university, Beijing, China, 1996.

[22] X. F. Wang and R. J. Cao, "Rubber asphalt modification mechanism," Journal of Chang'an University (Natural Science Edition), vol. 31, no. 2, pp. 6-11, 2011.

[23] H. C. An, Research on the Key Technologies for Application of Rubber Asphalt and its Mixture in Severe Cold Region, pp. 35-36, Chang'an University, Xi'an, China, 2017.

[24] L. Walubita, G. Martinez-Arguelles, and H. Chunduri etal, "Statistical evaluation of the material-source effect on the 
ductility and elastic recovery (ER) of plant-mix extracted asphalt-binders," Advances in Civil Engineering, vol. 2020, Article ID 8851691, 12 pages, 2020.

[25] H. Yin and Y. Li, "Interaction in a vehicle asphalt pavement coupled system," Journal of Vibration and Shock, vol. 32, no. 20, pp. 107-112, 2013.

[26] International Organization for Standardization, Iso/Tc 108/ Scn67, First draft proposal ISO/DP 860 for mechanical vibration-road Surface Profiles-Reporting Measured Data, International Organization for Standardization, Geneva, Switzerland, 1984.

[27] China National Standards, Gb 7031-86, Vehicle VibrationDescribing Method for Road Surface Irregularity, China National Standards, Beijing, China, 1986.

[28] X. J. Deng and L. Sun, Vehicle-ground Structural System Dynamics, China Communication Press, Beijing, China, 2000.

[29] F. Yu and Y. Lin, Vehicle System Dynamics, China Machine Press, Beijing, China, 2005.

[30] C. F. Yang, S. Xie, and J. S. Sun, "Vehicle dynamic load coefficient analysis based on pavement roughness," Journal of Chongqing Jianzhu University, vol. 34, no. 4, pp. 77-80, 2015.

[31] X. X. Rong, J. H. Li, J. He, and F. S. Deng, "Effect analysis of vehicle system parameters on dynamic response of pavement," Mathematical Problems in Engineering, vol. 2015, Article ID 561478, 8 pages, 2015.

[32] Y. Hou, Z. Y. Guo, and B. Tian, "Dynamic deflection response of layered pavement structure subjected to dynamic load," China Journal of Highway and Transport, vol. 3, pp. 8-12, 2002.

[33] H. J. Li and X. M. Huang, "Axle load conversion formula based on deflection equivalent for semi-rigid base asphalt pavement under heavy-load," Journal of Highway and Transportation Research and Development, vol. 7, pp. 5-8, 2004.

[34] X. Li, Research of Vehicle Dynamic Load and Pavement Mechanical Response, pp. 43-55, Taiyuan University of Technology, Taiyuan, China, 2013. 